Victor Lux TONN

DOI : $10.14746 /$ pp.2018.23.4.10

Salve Regina University, USA

https://orcid.org/0000-0003-4564-4523

Chen WENDIAN

Tunghai University, Taiwan

https://orcid.org/0000-0001-5022-8749

Hsi C. LI

Bryant University, USA

https://orcid.org/0000-0001-7924-3467

\title{
National Income, Strategic Discontinuity, and Converging Trajectories of Macroeconomic Policy Initiatives: An Empirical Study of China
}

\begin{abstract}
The framework of converging trajectories of macroeconomic policy initiatives is employed in the context of strategic discontinuity to study the national income of an advancing economy. A model of systemic changes based upon an equation of production and consumption is presented. In this study of the Chinese economy of 1980-2014, over time, the dynamics of policy imbalance is found to decrease considerably, which is consistent with the decreasing trend of shrinking the differences among the impact coefficients of government consumption, private investment, and private consumption.
\end{abstract}

Key words: strategic discontinuity, systemic changes, econometric testing, advancing economy, China

\section{Introduction}

$\mathbf{T}$ his paper accounts for a basic framework of the national income of a convergent mixed system with an objective to provide a new theory to facilitate the study of the Chinese economy through revealing its converging trajectories of macroeconomic policy initiatives over time.

For a world economy of modern time, in the process of economic advancement, there are two prominent trends observed over time. For one, it is the convergence of pure market economy toward a mixed economy with pure capitalist production system mixed with (soft) socialist welfare system. For the second trend, it is the convergence of purely planned economy toward a mixed economy with partial socialism (i.e., welfare system and partial government production socialism) mixed with capitalist production system, with the latter based on private property rights.

In this first trend, Keynesian revolution represents the best example of the process of systemic transformations. It is well known that for the conventional theory represented by Keynesianism and new Keynesianism, macroeconomics has been developed on the basis of representative agents, complete rationality, and utility maximization. To the Keynesian approach, some roles of cultures and institutions are supplemented by institutional economics. Besides, new approaches with the concepts of incomplete rationality and even some contradictory behaviors of economic agents have been ad- 
vocated by behavioral economics, and the issue of heterogeneous agents has also been tackled.

In this paper, we shall address the problem of world convergence in a course of strategic discontinuity from the perspective of the second trend. In this second trend, to our knowledge, the role of government interventions in the forms of macroeconomic policies has not been fully addressed. To fill in a part of this gap, we shall present a model of systemic changes by focusing on the convergent aspect of the impact coefficients of the private consumption, private investment, and government's spending overtime. The idea is essentially is that, in this process of a planned economy convergent toward a mixed economy, the roles of government spending and investment (i.e., with the latter being a defining feature of planned socialist economy) would be weaken overtime, while the weight of the private consumption would be rising.

Then, to verify the consistency between this model of systemic changes and the reality, an empirical examination of the Chinese economy is then engaged. For this purpose, a study of the Chinese economy and its major courses of strategic turns 1980-2014 shall be presented in Sections 4 and 5. Furthermore, in Appendix B, the model of systemic changes of human activism (HA) comprising the forces of centrality (or government actions), mutuality/co-creativity (or the intermediate force between those of government and the private market), and competition (or market activities) is further provided to finish this paper.

\section{Systemic Changes of an Advancing Economy in States of Strategic Discontinuity}

Following the afore-mentioned convergent process of the second trend, in due course of economic advancement of a nation, let the mixed system comprise the forces of government consumption, private investment, and private consumption. In general, the evolution of the systemic structures of an advancing nation transforming from a planned economy into a mixed economy is staged as follows.

Stage 1. Government investment an consumption play the leading role of economic construction because the sector of private business is very small, and at this time national efforts are devoted to develop the basis of heavy and chemical industries. Therefore, from the perspective of consumption, government consumption dominates private consumption in creating the momentum of economic development. Nevertheless, for playing the constraining role, private consumption is still important since, in the long run, any increase in production must be matched by an increase in either government or private consumption.

Stage 2. By the growing strengths of private business and the gradual relaxation of government's restrictions on private consumption, now the momentum of economic development derives its growing strengths from private consumption, while the role of government consumption decreases relatively, due to the relative inefficiency of the central planning mechanism. That is, this centrally planned economy has been transforming into an early stage of mixed economy in which private business is gaining its importance over time. Thus, by the growing strengths of private business, private investment is playing an increasingly important role as well. 
Stage 3. As the mixed economy transforming from an extensive (or input-led) growth path into an intensive growth (or low and medium technology-led path and to some extent high-technology path), both government and private investments play the pivotal role in creating the growth momentum of this mixed economy.

Results. In sum, three results are derived from the above. (1) The force of strategic discontinuity of a system would not cease if the strategic objectives of the system are not achieved and if there exist potentials of systemic and strategic changes. (2) The force of strategic discontinuity of a system would not cease if the state of the system is not satisfactory and if there exist potential gains from systemic and strategic changes. (3) In the process of decreasing the degree of strategic discontinuity, the difference among the forces of government spending, private consumption, and private investment shall shrink; as such, the differential marginal contributions of these forces would shrink over time accordingly. ${ }^{1}$

\section{National Income Account Identity and a Model of Economic Advancement in States of Strategic Discontinuity}

In the above, we discussed various states of strategic discontinuity among the forces of government spending $(G)$, private investment $(I)$ and private consumption $(C)$ existing in the context of the (real) national income account identity. Below, a specific model of economic advancement in terms of these forces $(C, I, G)$ is created. Now, we shall briefly account for the traditions and ample rooms for refinement of the conventional national income account identity: $Y=C+I+G+X-M$ with the forces of exports $(X)$ and imports $(M)$ (see Equation (1)).

The framework of national income prevailing in the conventional macroeconomics has been developed from Keynesian theory of marginal propensity to consume to neoKeynesian economics that embraces AD-AS model, IS-LM model, and Phillips curve, etc. This Keynesian macroeconomics has recently been further developed into new Keynesian economics (Mankiw and Romer, 1991; and in models of dynamic stochastic general equilibrium, see for instance Jordi Galí, 2008; David Romer, 2012; Michael Woodford, 2003) in which microeconomic foundations (originally rooted in the system of general equilibrium) are provided. In essence, the major themes of New Keynesian economics concern with forward expectations of households and firms and the role of government interventions more through monetary policy than fiscal policy necessitated by the imperfect competition of the markets in which prices and wages are sticky.

One other direction of Keynesianism has been evolved into the theories of postKeynesianism (Robinson, Eatwell, 1974; Kaldor, 1980; Davison, 2007; Sraffa, 1960) in which the role of aggregate demand in dealing with long-term unemployment is emphasized (Wikipedia, 2015) and the financial instability of the monetary economy is predicted (Minsky, 1957, 1992).

Now we turn to the model of strategic discontinuity and its trajectory of convergence. Seeking to establish conditions of strategic discontinuity in terms of providing a general framework for the operation of a macro-advancing economy, let $\mathrm{P}$ be the price index,

${ }^{1}$ For the culture-political and economic structures of the Chinese economy, one may also see Tonn (2016) and Tonn (2018). 
TC the real costs of national production, $\mathrm{Q}$ the real GDP, G the government expenditure, I the private investment, and $\mathrm{C}$ the private consumption. Furthermore, let $\mathrm{Q}$ be a function of G, I, and C: $Q=\mathrm{f}\left(Z\left(\chi \psi_{G}\right), M\left(\chi \psi_{I}\right), \Gamma\left(\chi \psi_{C}\right) \mid \chi \downarrow \chi_{0}\right)$, for $\psi_{G}, \psi_{I}$, and $\psi_{C}$ being exogenous strategic factors and $1 \geq \chi_{0} \geq 0$.

For the national surplus $\Pi=P Q-T C+N$, with $\mathrm{N}$ (as a function of $\mathrm{G}$, I, and $\mathrm{C}$ ) being a factor of non-optimization, $P Q$ be the value of total output and $T C$ be the total costs, a necessary condition is then:

$$
\frac{\partial \ln Q}{\partial \ln G}=a \frac{\partial \ln Q}{\partial \ln I}+b=c \frac{\partial \ln Q}{\partial \ln C}+d
$$

where $Q=\mathrm{f}\left(Z\left(\chi \psi_{G}\right), M\left(\chi \psi_{I}\right), \Gamma\left(\chi \psi_{C}\right) \mid \chi \downarrow \chi_{0}\right)$, for $Q=f($. $)$ denoting the function with $\chi_{0}>0$, and $a \downarrow a_{0}, b \downarrow b_{0}, c \downarrow c_{0}, d \downarrow d d_{0}$, for $a_{0} \geq 1, b_{0} \geq 0, c_{0} \geq 1, d_{0} \geq 0$.

That is, although in general the dynamic trajectory of strategic discontinuity may either be strengthened or weakened over time, for an advancing economy traversing away from the direction of high-level government control and low-level private initiatives, as in the case of the Chinese economy in the process of development and growth, the variables $\chi$, $\mathrm{a}, \mathrm{b}, \mathrm{c}$, and $\mathrm{d}$ shall all point to the convergent trend toward low-level strategic discontinuity. That is, for the sake of achieving modernity, coefficients of these variables' respective marginal contributions in percentage terms as series of natural numbers must eventually converge to a vicinity of absolute equality. As the development of economic structure proceeds well, the space of strategic operations and the scope of strategic discontinuity contract over time by the internal laws of motion. Simultaneously, the efficiency or marginal contribution in percentage term of the government expenditure would increase while that of the private consumption would decrease. As for the private investment, it is related but neutral to the strategic positions of the private and public sectors and is also well connected to the operational mode of the domestic economy as well as that of the global economy. As such, logically in terms of its direction of strategic momentum, the private investment is expected to follow the generally growing trend of the economy.

Now, to facilitate our econometric study of the Chinese economy (presented in the next section for being compatible with the context of the national income account identity), in this section, starting with the equation of production and consumption, we shall convert this equation of production and consumption into a form more comprehensive than that of the conventional approach. To bridge the gap between Equation 1 and the conventional approach of national income identity, let $y, c, s, c^{G}, s^{G}$, and $f$ be the real measures of GDP, private consumption, private saving, government saving, government investment, and net exports (or foreign sector), respectively. Then, for $y$ being the real GDP of production and consumption, let the equation of saving and consumption be:

$$
y^{-}=c+s+c^{G}+s^{G}+f
$$

Assume that $s=\xi i+\beta=i+\beta^{\prime}+\beta=i+\beta^{\prime}$, for $i$ being the private investment, $\xi$ the factor of productivity of the private investment; and $\beta$ " $=\beta+\beta$ ' a constant. Furthermore, assume $s^{G}=\xi^{G} i^{G}+\alpha=i^{G}+\alpha^{\prime}+\alpha=i^{G}+\alpha$ ", for $i^{G}$ being the government investment, $\xi^{G}$ the productive factor of the government investment, and $\alpha^{\prime \prime}=\alpha^{\prime}+\alpha$ a constant. Besides, let the national income account identity be: $y=c+i+g+f$, for $i$ denoting the private investment and $g=c^{G}+i^{G}$. From the above reasoning, it derives: 
$y=c+\xi \iota+c^{G}+\xi^{G} \iota^{G}+f+(\alpha+\beta)=c+i+\left(c^{G}+i^{G}\right)+f+\left(\alpha^{\prime \prime}+\beta^{\prime \prime}\right)$. It follows then:

$$
\begin{gathered}
y=c+(\xi i+\beta)+\left(g^{\#}+\alpha\right)+f, g^{\#}=c^{G}+\xi^{G} i^{G} \\
y=c+i+g+f+\rho, g=c^{G}+i^{G}
\end{gathered}
$$

Equation (2) is the equation of production and consumption with $\rho=\alpha^{\prime \prime}+\beta^{\prime \prime}$ representing the forces of "private and government productivity" as the linearly approximation of the term $(\xi \phi)^{\mathrm{b}}$ (introduced below, corresponding to the term $\mathrm{b} \tau$ in Equation (2)). The logarithmic form corresponding to Equation (2) is $y=\operatorname{cig} f(\xi \phi)^{b} \sim(c+i+g+f+\rho)$ , with $\varphi$ and $b$ being constants, and $\rho$ as the "force of production" representing the factor of approximation in the process of linearization.

By reasonable assumptions, it is seen from Equation (3) that the greater value of $\left(g^{\#}=c^{G}+\xi^{G} i^{G}\right)$ would increase the value of $y$ by assuming $\xi \geq 1, \xi^{G} \geq 1,\left(\alpha^{\prime \prime}+\beta^{\prime \prime}\right)>0$, and holding all others constant. This means the increase in the modified government expenditure $g^{\#}$ (with positive effects of $\xi^{G}$ and a neutral or positive effect of $\xi$ ) is beneficial to the economy with all other variables remain constant (for instance, at a time of severe economic crisis).

Let $\mathrm{y}^{\text {Conv }}$ depict the real GDP of the (conventional) national income account identity: $y^{\text {conv }}=c+i+g+f$. Then, by denoting $\mathrm{c}$ as $c^{\#}$, from Equation (4), it derives: $y-y^{\text {Conv }}=\left(c^{\#}-c\right)+(\xi i-i)+\left(\xi^{G} i^{G}-i^{G}\right)+(\alpha+\beta)$, and thus:

$$
\left(-g^{\#}\right)=-\left(y-y^{\text {conv }}\right)+\left(c^{\#}-c\right)+(\xi-1) i-g+(\alpha+\beta)
$$

Equation (3) implies that as $\left(-g^{\#}\right)$ increases, both $\left(c^{\#}-c\right)$ and $(\xi-1) i$ would increase, by holding all others constant. This is true because $c^{\#}>c$ and $\xi>1$ due to the assumed positive effects of government actions on $c^{\#}$; for example, reducing $g^{\#}$ would leave more income for the private consumption and investment through time lags.

Below, for the model of economic advancement, in order to prepare for transforming into a logarithmic form, let the production function be: $y=\operatorname{cig} f(\xi \phi)^{b}$, for $\mathrm{b}$ and $\phi$ being the adjustment factors (i.e., to help induce $\xi$ to adjust so that $y=\operatorname{cigf}(\xi \phi)^{b}$ in corresponding to the process of linearization). Then, the following formula can be derived as follows:

$$
Y(t)=C(t)+I(t)+G(t)+F(t)+b \tau
$$

with $\ln \tau=\ln \xi \phi=\ln (\gamma \kappa \ell k)+\ln \phi, C(t), I(t), G(t)$, and $\mathrm{F}(\mathrm{t})$ being the real output generated by the private consumption, government expenditure, and net exports, respectively in logarithmic forms. Essentially, Equation (4) explicates the real GDP as a weighted average of " $C+I+G+F$ " and $\tau$ with weights of 1 and $b$ respectively, with this $\tau$ as the "force of production" (corresponding to $\rho$ in linear approximation) being consistent to Blanchard and Quah's (1989)'s concept of productivity.

The economic system involving Equation (6) is made complete by the inclusion of the following formulae. That is, the production function is $y(t)=\ell^{\zeta} \kappa^{\theta} k^{\eta}(t)$; 
$C(t)=H(y)+\pi P(t)$, the private consumption in logarithmic form $(\mathrm{c} \ln (\mathrm{c}))$ is a function of real output of the economy in logarithmic form (i.e., $H(y)=\ln (h(y))$ plus the price index P multiplied by a constant $\pi$. Here, $P(t)=\ln (p), p(t)=\mu m(t)$, with $p$ being the price level as a positive function of " $m$ " at time $t$, " $m$ " the fixed level of money supply, and $\mu$ the weight associated with " $m$ ". Therefore, $P(t)=M(t)+M_{0}$, $M(t)=\ln (m(t)), M_{0}=\ln (\mu)$. In addition, let $\mathrm{L}(t)=N(t)+L_{0}, L(t)=\ln \ell(t)$, and $N(t)=\ln (n(t))$ for $\mathrm{n}(\mathrm{t})=\mathrm{n}(\mathrm{t}-1) \ell_{0}$ being the population of time $\mathrm{t}$, and $\ell_{0}$ a constant. Note once again that all variables written in in capital letters are in logarithmic forms.

In the production function, $\ell$ stands for the employment of labor under constant technology, $\zeta$ stands for the culture-institutional coefficient associated with $\ell, \mathrm{k}$ stands for the capital stock under constant technology, and $\kappa$ stands for the technological factor associated with $\mathrm{k}$; so that $y(t)=\ell^{\zeta} \kappa^{\theta} k^{\eta}(t)$, with $\zeta, \theta$, and $\eta$ being constants.

Consider $\varepsilon_{S}(t)$ as the "production residual" and $\varepsilon_{D}(t)$ the "consumption-plus residual". Then, by introducing lag terms of time and for $\varepsilon_{S}(t)$ corresponding to $b \tau$ and $\sum_{j=1}^{p-1} b_{j} \varepsilon_{D}(t-j)$ to " $C(t)+I(t)+G(t)+F(t)$," Eq. (6) leads to the following equation: $Y(t)=\varepsilon_{S}(t)+\sum_{j=1}^{p-1} b_{j} \varepsilon_{D}(t-j)$. Therefore, it derives:

$$
\Delta Y(t)=\varepsilon_{S}(t)-\varepsilon_{S}(t-1)+\sum_{j=1}^{p-1} b_{j}\left[\varepsilon_{D}(t-j)-\varepsilon_{D}(t-j-1)\right]
$$

\section{The Chinese Economy and Its Major Courses of Strategic Turns 1980-2014}

Following the theories formulated in the above, an econometric study of China is presented below in Section 5 to check whether the essential features of its three-stage development (also see Results of Appendix B) is substantiated.

Before turning to this econometric study, we shall have a brief account of the process of economic transformations of the Chinese economy. Since 1949, the economy of China (i.e., PRC) has experienced uneven paces of economic development and growth. Nevertheless, from 1949 to 1978, its annual average real GDP growth rate was approximately 4.2\%; and from 1978-2014, this growth rate was approximately $9.4 \%$. Note that it was approximately $9.9 \%$ in the period $1989-2007$ and $8.8 \%$ in the period $2007-2014$.

Since 1978, China initiated its drive for modernization through learning significantly from its East Asian neighbors and countries of capitalism. Over time, China's economic system transformed away from that of quasi-Soviet-type socialism in 1978 to a partially marketized new system. In this new system, the role of government expenditure remains strong, while the roles of private investment and consumption gain their surging momentum over time.

The Chinese economy has so far exhibited major features of special Chinese characters (Shi, 2010, logically related to Steven Cheung's theory of tenants), rapid economic growth (Guo, 2007; Hu, Khanp, 1997; Lin et al., 1997; Lin, 2010; Yueh, 2013; Zhang, 2013; Chris, 2014), rapid infrastructural, industrial, and technological growth (Dees, 1998, Cao et al., 2009; Kwan et al., 1999; Ning, 2009; Sahoo et al., 2012; Yueh, 2013), socialist market and SOEs (Chang, 2012; Hu, 2012), regional balance (Démurger, 2001), 
capital investment and rapid trade expansion (Qiao, 1998; Lin, 1999; Kwan et al., 1999; Turpin, Liu, 2000; Graham, Wada, 2001; Lum, Nanto, 2002; Qin et al., 2005; Cao et al., 2009; Serger, 2009; Sharma, 2009; Gutrie, 2012; Sahoo et al., 2012), significant or nonbeneficial FDI inflow (Wei et al., 2001; Liu et al., 2002; Serger 2009), and privatization and Washington consensus (Zhang, 2012; Williamson, 2012; Wu, 2013). ${ }^{3}$

In general, the economic reforms in the 1970's are prompted by the low level productivity of the agricultural sector under People's commune and that of the industrial sector under central planning.

One problem of low agricultural productivity under People's commune was partially caused by the low morale under rigid management system of the central planning mechanism. In People's commune, the reward to peasant does not correspond to one's efforts. This system retarded one's enthusiasm for production and provided no opportunity for individual and local initiatives. In terms of resource allocation, beyond the issue of insufficient inputs allotted to the agricultural sector, due to the guiding principle of subsidizing industrial development by drawing upon agricultural resources under Soviet-type planning (modified to fit the Chinese reality), the missing of effective market guidance is obvious. The role of market in a capitalist system is to employ price signals so that higher prices induce more outputs while lower prices decrease outputs. In this Chinese case of agricultural development, market mechanism is constrained by central planning and the social force of mutuality; and for the former, the planner does have an aggregate target and some essential means to increase the production of basic food staples (for instance, with generous tax treatments, fiscal subsidies, and even technical assistance), whereas for the latter, the agricultural productivity is fundamentally determined by the level of technology conditioned upon the force of mutuality - the level of engineering education and the quality of its scientific or R\&D community.

It is easily seen that the relationship between market and central planning mechanism is more than the conventional Western wisdom of price signals. Even though the central planner is hard to calculate and obtain the correct prices to guide the SOEs, the market may not generate correct prices in order to foster the stability of the market and to promote technological progress. Nevertheless, the market does help to generate effective price signal in some cases. And yet the market is most likely distorted by reasons well beyond the market imperfection of oligopoly and monopoly, attested by the phenomena of imperfect information, risk and uncertainty, human's partial irrationality, adverse selection, and moral hazard, and etc., the interventions of socio-political forces (for instance, corruption and over and covert social and racial biases), and the external adversary forces of global economic development.

Below, the Chinese economy up to 2014 is divided into three periods. In the first period 1980-1988, there were at first the introduction of household responsibility system allowing peasants to profit from raising the productivity of agricultural activities and later the industrial reforms to allow SOEs to have substantial autonomy in management (Lin et al., 1999).

In terms of our model of systemic advancement, the development of household responsibility system (also see ADV 1 of Appendix B) was designed to partially incorporate the forces of individual creativity and market competition, and industrial reforms (also see ADV1 of Appendix B) were designed to improve the operational efficiency of centrality. 
Beyond the introduction of modern fiscal and monetary policies (related to ADV1 of Appendix B), the tax sharing system between the central and local governments was also established in 1994 to improve the efficiency of centrality. Over all, one may consider the essential direction of 1990s as a movement inclining somewhat toward Washington Consensus (Zhang, 2012, p. 189) while retaining a significant role of central planning.

In the second period 1989-2007, China stepped up its reforms of state-owned enterprises and financial market including the new development of stock exchanges, partially flexible exchange rate, and the creation of other financial institutions.

This movement of financial reforms was designed to improve the market efficiency and to serve as a first step toward eventual integration into the global economy (see ADV 2 of Appendix B). At times, government debts rose rapidly, and China joined WTO in 2001. China's private enterprises started to gain a greater share of employment than that of government enterprises in the 1990s (Cheng, 2007; Hu, 2010), and even secured a larger share of output than their government counterparts after year 2000. This enlargement of the role of private enterprises (resulted from ADV1 of Appendix B) leads to the high-level efficiency of the individual's creativity and the force of market competition is further promoted.

In the third period 2008-2014, the overall economic momentum of China was directed toward balancing between the real and financial production, between the coast and inland development, between the domestic consumption and export expansion, and between technological imitation-modification and invention-innovation (also see ADV 4 of Appendix B). ${ }^{2}$

In this period, by the impact of 2007-2009 Great Recession of the West and the increasing wage rates of the domestic economy, the external demand for Chinese exports have significantly reduced. This causes the marginal contribution of private investment to decrease. To compensate for this economic down turn, Chinese government's stimulus packages of four trillion yuans (He et al., 2009) have contributed to the marginal impact of government consumption onto the economy. By its very nature, this is more than a conventional type of Keynesian stimulus, since it is operated under the guidance of central planning (or the Committee for National Development and Reforms).

Then as the Chinese economy transformed from a centrally planned economy of production to a system of human activism (or mixed economy), only a much smaller space is left for major economic overhaul, except in the directions of stimulating domestic consumption, international financial integration, and technological invention and innovation.

In sum, to gain efficiency of operations overtime, in China the force of government operations or government consumption shall dwindle, while the momentum of private activities or private consumption shall gradually ascend. The above observations do confirm this direction of strategic evolution of China in its three periods of moving toward the direction of ever higher level of modernity with the reducing momentum of strategic discontinuity over time.

${ }^{2}$ One may see Tonn (2014). Strategically speaking, the overall direction of China's economic advancement has been the pursuit of an innovative or "leap strategy" to bypass the "conventional world center" or the politico-economic and military strengths of its rivals (for example, internally in engaging disproportionally in developing high-technological industries and technologies of outer space exploration, and externally in forming quasi-alliances with third world countries). By the force of the centrality or government in states of strategic discontinuity, China attempts to create a new center or order of the world (Tonn, 2009, pp. 180-183). 


\section{A Case Study of the Advancing Economy of China}

For the Chinese economy of the period 1980-2014, the data is chosen from Oxford Economic Database (with seasonal adjustment and deflated by prices, in US dollars). The variables studies are $G D P_{t}$ (amount of real gross domestic product), $C_{t}$ (amount of real private consumption), $I_{t}$ (amount of real private investment), $F D I_{t}$ (amount of real foreign direct investment), $G_{t}$ (amount of real government consumption, $X$ (amount of real exports), and $M_{t}$ (amount of real imports).

For the period of 1980Q1-2014Q4 with 140 points of quarterly observations, the data is plotted and presented below as the trends of variables in logarithmic form.

Figure 1. Trends of Variables in Logarithmic Form

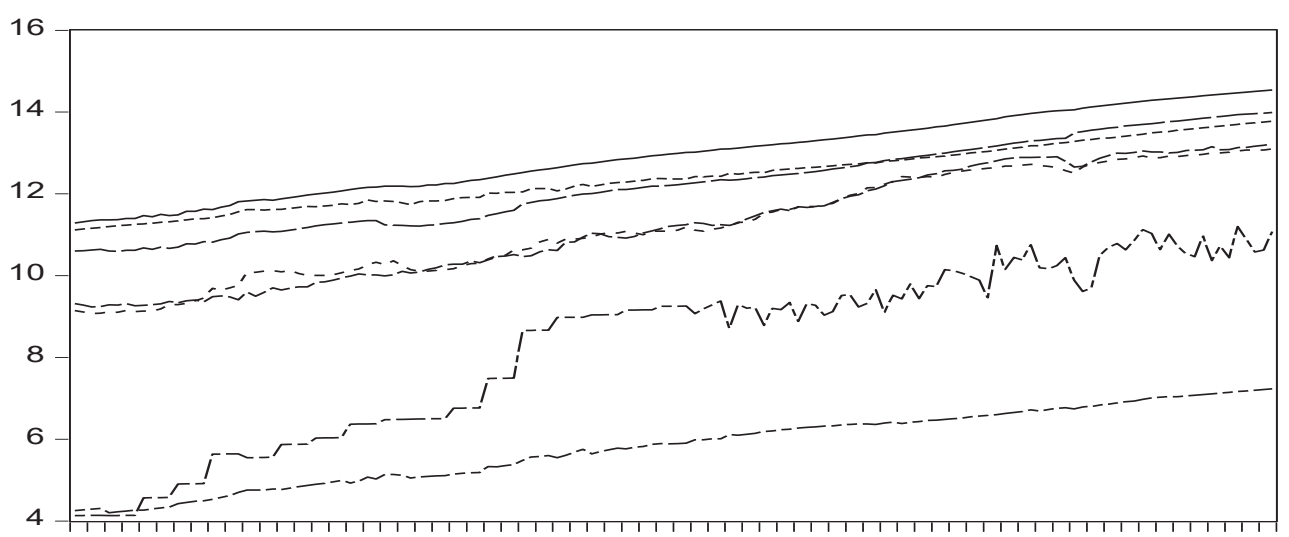

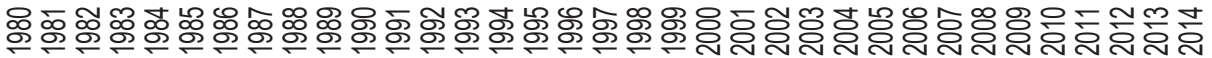

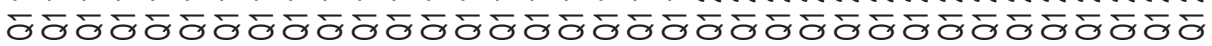

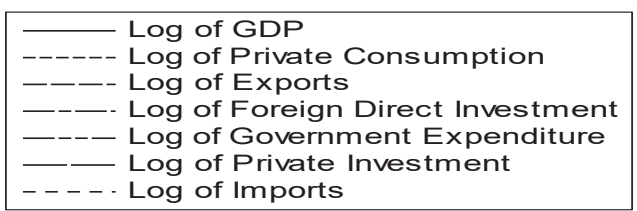

Let the vector of variables be: $\mathrm{Y}_{\mathrm{t}}^{\prime}=\left[\log G D \mathrm{P}_{\mathrm{t}} \log \mathrm{C}_{\mathrm{t}} \log \mathrm{I}_{\mathrm{t}} \log \mathrm{G}_{\mathrm{t}} \log \mathrm{X}_{\mathrm{t}} \log \mathrm{M}_{\mathrm{t}} \log F D \mathrm{I}_{\mathrm{t}}\right]$. This $Y_{t}$ may not be a stable series. For a regression model like this to be tested, the problem of spurious regression may spring up; and long-term trend and the interactive relationship between long-term and short-term adjustments may not be accurately detected. Thus, the Vector Error Correction Model (VECM) is chosen and tested in order to verify whether any long-term stable relationship exists. After positive identification of this relationship, one shall then proceed to estimate the long-term coefficients of interactive relationships among variables and their short-term impacts. In this juncture, Equation (6) derived below represents what are in states of strategic discontinuity for the reasons provided previously in Section 3 and later in assessing the values of C, I, G, and so on in the empirical study of the Chinese economy. 
From Equation (5) of Section 3, our empirical model is constructed as follows:

$$
\Delta \mathrm{Y}(\mathrm{t})=\gamma_{1}+\delta_{1} \mathrm{t}+\alpha\left(\beta^{\prime} Y_{t-1}-\gamma_{2}-\delta_{2} \mathrm{t}\right)+\sum_{\mathrm{j}=1}^{\mathrm{p}-1} D_{j} \Delta Y_{t-1}+\epsilon_{t}
$$

with $t$ being the trend variable, $\Delta Y_{t}$ the difference of $Y_{t}, \gamma_{1}$ and $\gamma_{2}$ the intercepts, and $\delta_{1}$ and $\delta_{2}$ the coefficients of the trend (for determining which whether or not to incorporate the intercepts and trend variables). Since $\beta$ ' depicts the coefficient of long-term stable relationship among variables and $\beta^{\prime} Y_{t-1}-\gamma_{2}-\delta_{2} t \neq 0, \Delta Y_{t-1}$ would affect $\Delta Y_{t}$ through the coefficient $\alpha$.

In estimation, through difference variables and the canonical correlation obtained by distracting serial effects from the difference variables, one would verify whether there is any co-integration relationship or stable relationships among variables. As such, $\Delta Y_{t}$ accounts for the amount of short-term variation, while $\beta^{\prime} Y_{t-1}$ explores long-term stable relationship.

For selecting the appropriate model, we shall adhere to Schwarz Criteria (SC) and follow the rules of MacKinnon-Haug-Michelis (1999) or VAR model without any constant terms and ECM term with constant terms: $\gamma_{2} \neq 0, \gamma_{1}=\delta_{1}=\delta_{2}=0$. For the table providing information of model selection, see Appendix A.

Below, we analyze the data for periods of 1980-1988, 1989-2014, 1989-2007, 2008-2014.

(1) The period 1980-1988. By the pairwise Granger causality test (Engle, Granger, 1987), the following results are detected. The first level of Granger causality is: $\mathrm{C} \rightarrow$ GDP (very significant impact); the second level is: FDI $\rightarrow$ GDP, I $\rightarrow$ GDP, G $\rightarrow$ FDI, and $\mathrm{X} \rightarrow$ GDP significant impacts); the third level is: $\mathrm{M} \rightarrow \mathrm{GDP}$, and FDI $\rightarrow$ GDP (impacts being not that significant); and the surprising effect: $\mathrm{G} \rightarrow-\mathrm{GDP}$ (see the explanation for Equation (3) in Section 3).

For this period, by employing a Johansen co-integration model (JCM) to take into account the relationships between long-term and short-term adjustments, the results are as follows:

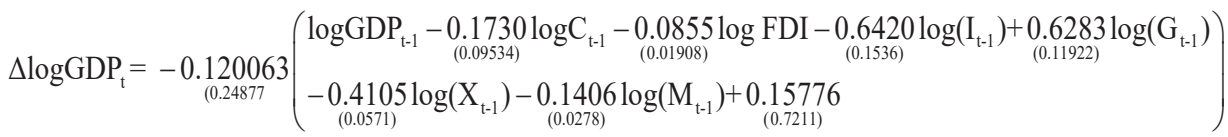

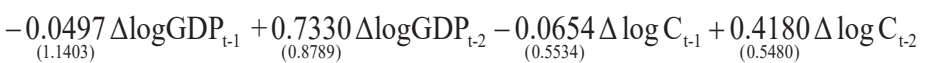

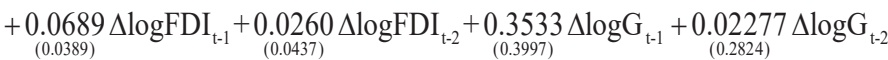

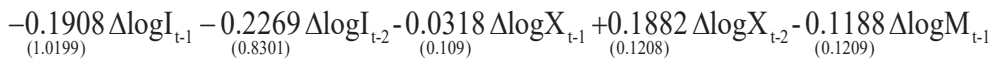

$$
\begin{aligned}
& -\underset{(0.1075)}{0.046} \Delta \log \mathrm{M}_{\mathrm{t}-2}+\mathrm{e}_{\mathrm{t}}
\end{aligned}
$$

$\mathrm{R}^{2}=0.527980$, Adjusted $\mathrm{R}^{2}=0.180177, \mathrm{SSE}=0.012324$, S.E. of equation $=0.025468$, F-statistic $=1.518041, \log$ Likelihood $=86.44004$, the individual equation's AIC $=$ $=-4.202355, \mathrm{SC}=-3.528961$.

From the CCR model of 1980-1988, it derives:

$$
\begin{aligned}
\ln y_{t} & =\underset{(0.0634)}{0.7495} \ln C_{t}+\underset{(0.1005)}{0.2523 \ln I_{t}}+\underset{(0.080)}{0.1415 \ln G_{t}}+\underset{(0.0350)}{0.1163} \ln X_{t}-\underset{(0.0205)}{0.0765} \ln \mathrm{M}_{\mathrm{t}} \\
& +\underset{(0.0112)}{0.0197 \ln F D I_{t}}-\underset{(0.5713)}{0.7729+\eta_{t}}
\end{aligned}
$$


(2)Theperiod of 1989-2014. By the pairwise Grangercausality test, the following results are detected, and the directions of impacts are: I $\rightarrow$ GDP, I $\rightarrow$ FDI, GDP $\rightarrow$ G,I $\rightarrow$ G,G $\rightarrow$ FDI (coefficient positive and small).

Below, through testing a Johansen co-integration model, the long- and short-term coefficients and adjustment coefficients are reported in Equation (11) and Equation (12) is derived by testing a CCR model.

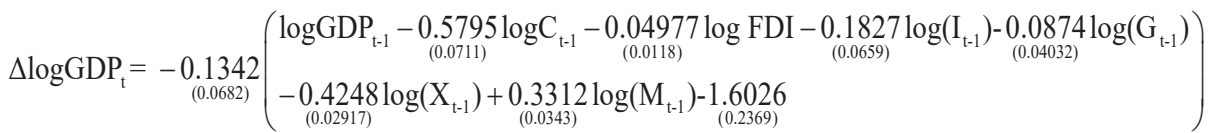

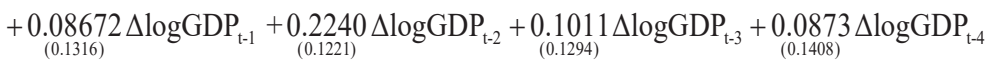

$$
\begin{aligned}
& -\underset{(0.0758)}{0.0293 \Delta} \Delta \log C_{t-1}+\underset{(0.0774)}{0.0618 \Delta \log C_{t-2}}+\underset{(0.0700)}{0.1427 \Delta} \Delta \log C_{t-3}-\underset{(0.0704)}{0.0342 \Delta} \Delta \log C_{t-4} \\
& -\underset{(0.0258)}{0.0299} \Delta \log \mathrm{X}_{\mathrm{t}-1}-\underset{(0.0275)}{0.0090} \Delta \log \mathrm{X}_{\mathrm{t}-2}+\underset{(0.0253)}{0.0110} \Delta \log \mathrm{X}_{\mathrm{t}-3}-\underset{(0.0274)}{0.0552} \Delta \log \mathrm{X}_{\mathrm{t}-4} \\
& +\underset{(0.0039)}{0.0002} \Delta \operatorname{logFDI}_{\mathrm{t}-1}+\underset{(0.0038)}{0.00076 \Delta \log \mathrm{FDI}_{\mathrm{t}-2}}-\underset{(0.0040)}{0.0006} \Delta \log \mathrm{FDI}_{\mathrm{t}-\mathrm{3}}+\underset{(0.0037)}{0.00089} \Delta \operatorname{logFDI} \mathrm{t}_{\mathrm{t}-4} \\
& -\underset{(0.0590)}{0.0594} \Delta \log G_{t-1}-\underset{(0.0544)}{0.1134} \Delta \log G_{t-2}-\underset{(0.0555)}{0.1178} \Delta \log G_{t-3}+\underset{(0.0532)}{0.03433} \Delta \log G_{t-4} \\
& +\underset{(0.0534)}{0.1310 \Delta \log \mathrm{I}_{\mathrm{t}-1}}+\underset{(0.0597)}{0.1734} \Delta \log \mathrm{I}_{\mathrm{t}-2}-\underset{(0.0641)}{0.01196 \Delta \log \mathrm{I}_{\mathrm{t}-3}}-\underset{(0.0611)}{0.02283 \Delta \log \mathrm{I}_{\mathrm{t}-4}} \\
& +\underset{(0.0285)}{0.01605 \Delta \log \mathrm{M}_{\mathrm{t}-1}}-\underset{(0.0282)}{0.0262} \Delta \log \mathrm{M}_{\mathrm{t}-2}-\underset{(0.0251)}{0.0101} \Delta \log \mathrm{M}_{\mathrm{t}-3}-\underset{(0.0252)}{0.0487} \Delta \log \mathrm{M}_{\mathrm{t}-4}+\mathrm{e}_{\mathrm{t}}
\end{aligned}
$$

$\mathrm{R}^{2}=0.306028$, Adjusted $\mathrm{R}^{2}=0.020275, \mathrm{SSE}=0.004469$, S.E. of equation $=0.008107$, F-statistic $=1.070953, \log$ Likelihood $=346.6465$, the individual equation's AIC $=$ $=-6.549413, \mathrm{SC}=-5.779654$.

Figure 2. The charts of Relevant Variables Logarithmic Forms (JCM), China, 1989-2014

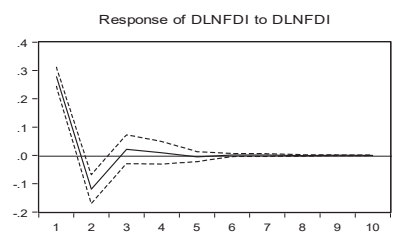

Response to Cholesky One S.D. Innovations?2 S.E.
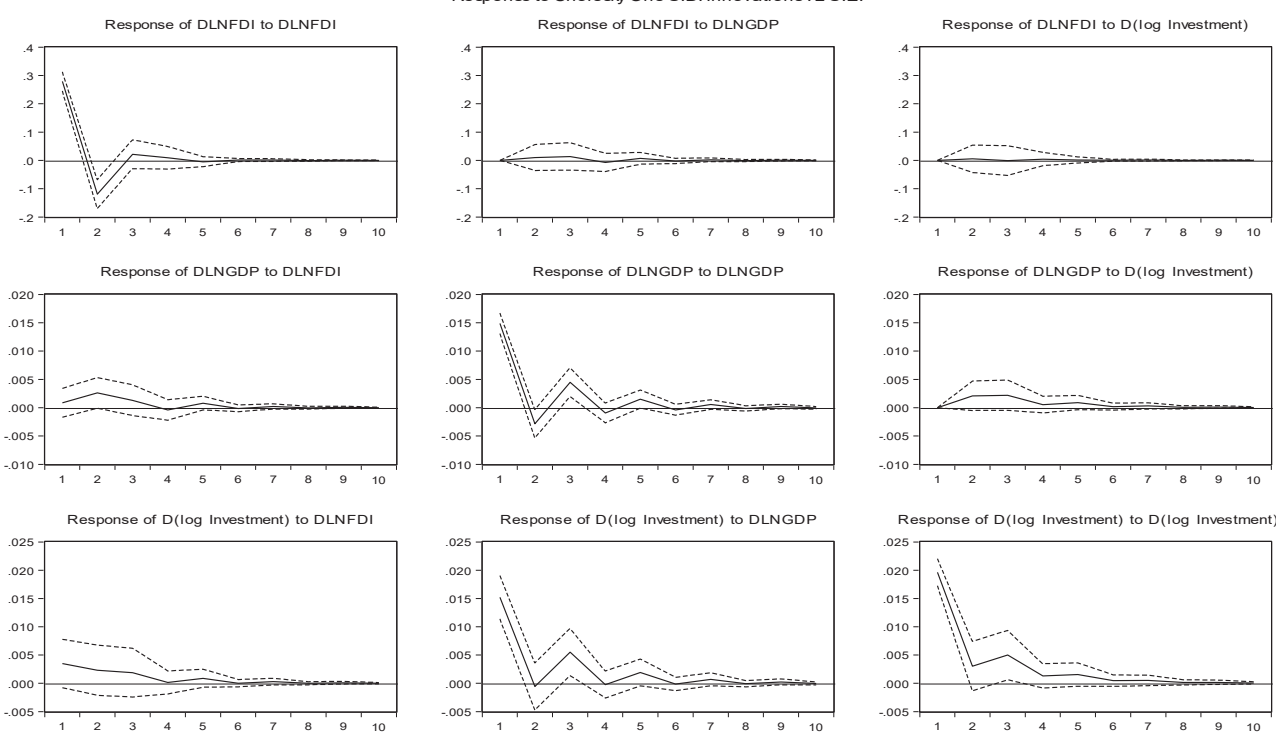


$$
\begin{aligned}
\ln y_{\mathrm{t}} & =\underset{(0.0544)}{0.3195} \ln C_{t}+\underset{(0.0206)}{0.2360} \ln X_{t}-\underset{(0.0067)}{0.0201 \ln } F D I_{t}+\underset{(0.0270)}{0.1471 \ln G_{\mathrm{t}}} \\
& +\underset{(0.0520)}{0.462} \ln I_{t}-\underset{(0.0230)}{0.1623 \ln } M_{t}+\underset{(0.1948)}{1.9707+}+\eta_{t}
\end{aligned}
$$

(3) Period 1989-2007. Now we further break up the years 1989-2014 into two periods: 1989-2007 and 2007-2014. Below, the major results of Granger causality Test for the period 1989-2007 are: $\mathrm{I} \rightarrow$ G, GDP $\rightarrow$ I, FDI $\rightarrow$ GDP, GDP $\rightarrow$ FDI, I $\rightarrow$ FDI (at 5\% level of significance); and $\mathrm{I} \rightarrow \mathrm{G}, \mathrm{GDP} \rightarrow \mathrm{I}, \mathrm{FDI} \rightarrow \mathrm{GDP}, \mathrm{GDP} \rightarrow$ FDI, I $\rightarrow$ FDI, and G $\rightarrow$ I $(10 \%$ significance).

As the results of our testing, the charts of dynamic responses of these variables are recorded below.

Figure 3. Charts of Dynamic Responses of Variables (CCR), China 1989-2007

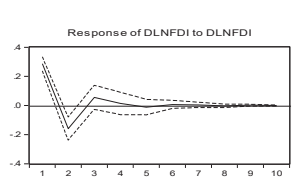

Response of DLNG to DLNFD

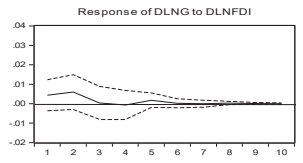

Response ofDLNGDP toDLNFDI

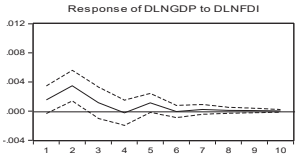

Response of DLNI to DLNFDI

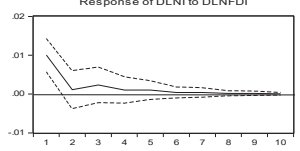

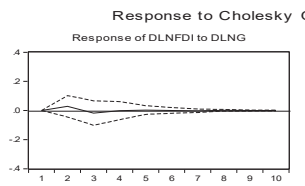

Response of DLNG to DLNG
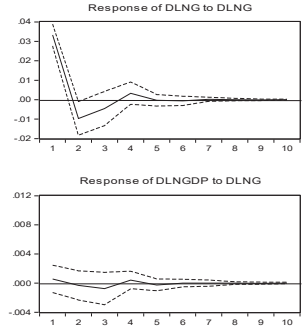

Response of DLNI to DLNG

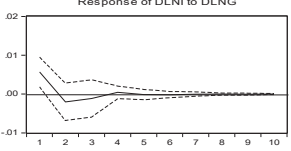

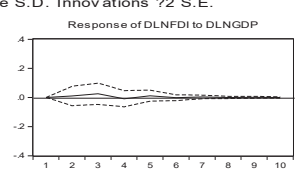
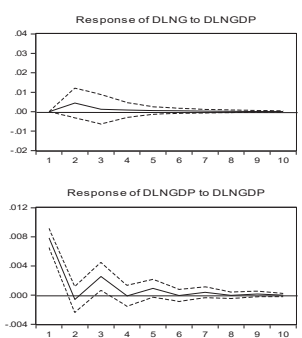

Response of DLNI to DLNGDP

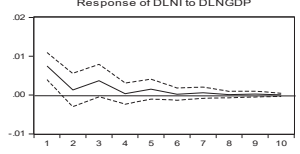

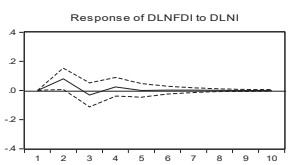

Response of DLNG to DLNI

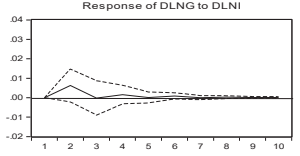

Response of DLNGDP to DLN

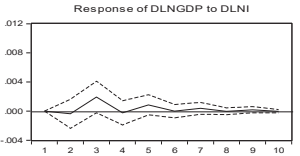

Response of DLNI to DLNI

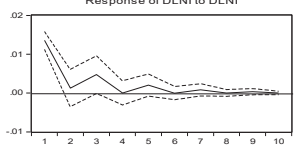

Then, by the method of canonical co-integration (CCR), the long-term relationships between these variables and GDP in the period 1989-2007 are revealed below:

$$
\begin{aligned}
\eta_{t}= & \log G D P_{t}-0.273-0.676^{*} \log C_{t}-0.386^{*} I_{t}+0.0112 \log F D I_{t} \\
& -0.078 G_{t}-0.139^{*} \log X_{t}+0.159^{*} \log \mathrm{M}_{\mathrm{t}}
\end{aligned}
$$

with FDI becoming statistically insignificant (i.e., without the sign $*$ ), $\eta_{\mathrm{t}}$ being the longterm coefficient of deviation in equilibrium, and the short-term adjustment coefficient to be -0.14077 .

(4) Period 2008-2014. In this period, it is discovered that the role of government consumption has improved significantly, and the government consumption apparently exerted a significant impact on GDP: G $\rightarrow$ GDP (at 5\% level of significance). In addition, the following sets of Granger causality are uncovered as well: G $\rightarrow$ GDP, GDP $\rightarrow$ FDI, $\mathrm{I} \rightarrow \mathrm{GDP}$ (at $10 \%$ level of significance). 
In the period 2008-2014, the method of canonical cointegrating regression (CCR) is employed with the results shown below.

$$
\begin{aligned}
\log G D P_{t} & =2.759+0.5102^{*} \log C_{t}+0.1436^{*} I_{t}+0.00088 \log F D I_{t} \\
& +0.2135^{*} G_{t}+0.0396^{*} \log X_{t}+0.0509^{*} \log \mathrm{M}_{\mathrm{t}}+\eta_{t}
\end{aligned}
$$

Judging from Equation (14), one of the results is what has been expected, the elasticity of government consumption with respect to GDP is moderate and yet relatively large. The value of the impact coefficient of G on GDP is 0.2135 , only smaller than that of private consumption (with the coefficient of 0.5102), but larger than that of private investment (with the coefficient to be 0.1436).

Figure 4. Charts of Dynamic Responses of Variables (CCR), 2008-2014
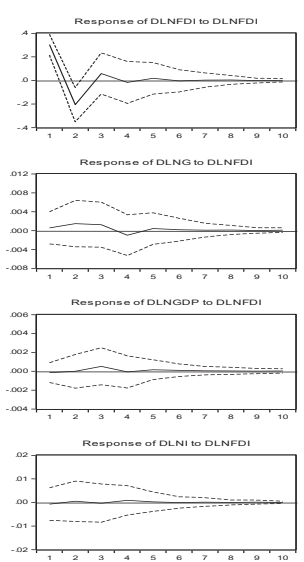
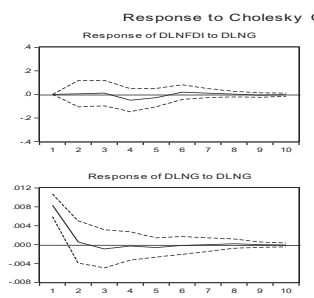

Response of DLNGDP to DLNO

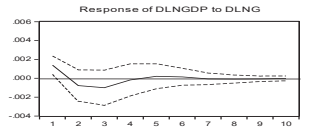

Response of DLNI to DLNG

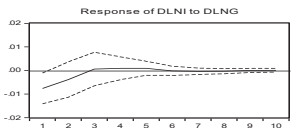

Innov ations ?2 S.E.
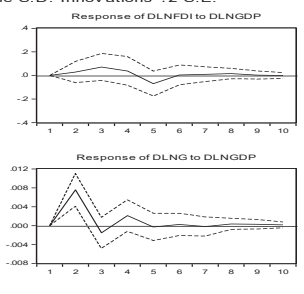

Response of DLNGDP to DLNGD
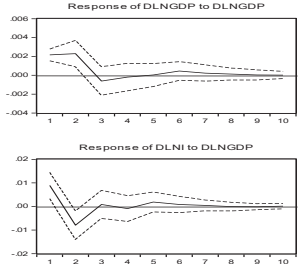
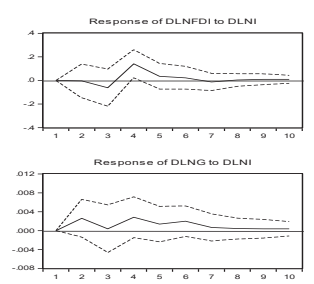

Response of DLNGDP to DLN

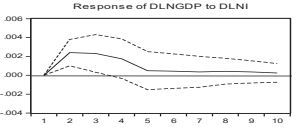

Response of DLNI to DLNI

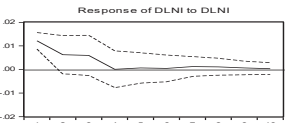

From the results of our testing, two tables and a figure recording the dynamic responses of these variables are presented below. As seen in Table 1 (with information drawn from Equations (9)-(14)), in general, in the Chinese economy 1980-2014, the impact coefficients of exports (X) on GDP have increased slightly over time (except a few years right after 1989). The impact coefficients of private consumption on GDP, as the most prominent factor detected in our study, have been decreasing over time. This appears to be the mirror reflection of the impact of government consumption with its coefficients being turned from a large negative (i.e., -0.6283 in 1980-1988, JCM $\square,_{1}$ ) to moderate positive numbers over time. As for the foreign direct investment (FDI) on GDP, its impact coefficients were found to be (relatively) small.

Table 1

\begin{tabular}{|c|c|c|c|c|c|c|}
\hline & $\begin{array}{c}\mathbf{1 9 8 0 - 1 9 8 8} \\
\text { CCR } \bigcirc,{ }_{1}\end{array}$ & $\begin{array}{c}\text { 1989-2007 } \\
\text { CCR } \bigcirc_{, 2}\end{array}$ & $\begin{array}{c}\text { 2008-2014 } \\
\text { CCR } \bigcirc_{, 3}\end{array}$ & $\begin{array}{c}1989-2014 \\
\text { CCR }\end{array}$ & $\begin{array}{c}\mathbf{1 9 8 0}-1988 \\
\text { JCM } \square,\end{array}$ & $\begin{array}{l}\mathbf{1 9 8 9 - 2 0 1 4} \\
\text { JCM } \square,{ }_{23}\end{array}$ \\
\hline 1 & 2 & 3 & 4 & 5 & 6 & 7 \\
\hline Government Consumption & 0.1415 & $0.078 !$ & 0.2135 & 0.1471 & -0.6283 & 0.0874 \\
\hline Private Investment & 0.2523 & 0.386 & 0.1436 & 0.4621 & 0.6420 & 0.1827 \\
\hline
\end{tabular}

Changing Pattern of Impact Coefficients on GDP, China, 1980-2014 


\begin{tabular}{|l|c|c|c|c|c|c||}
\hline \multicolumn{1}{|c|}{1} & 2 & 3 & 4 & 5 & 6 & 7 \\
\hline Private Consumption & 0.7495 & 0.676 & 0.5102 & 0.3195 & 0.1730 & 0.5795 \\
\hline Exports & 0.1163 & 0.139 & 0.0396 & 0.2360 & 0.4105 & 0.4281 \\
\hline Imports & -0.0765 & -0.159 & 0.0519 & 0.1623 & 0.1406 & $-0.3312 \dagger$ \\
\hline Foreign Direct Investment & 0.0197 & $-0.013 \dagger$ & $0.0009 !$ & -0.0201 & 0.0855 & 0.0498 \\
\hline
\end{tabular}

$\mathrm{G}=$ Government consumption, $\mathrm{I}=$ Private investment, $\mathrm{C}=$ Private consumption, $\mathrm{X}=$ Exports, $\mathrm{M}=$ Imports, FDI $=$ Foreign direct investment, $\mathrm{JCM}=$ Estimated through Johansen co-integration model, $\mathrm{CCR}=$ Estimated by the method of canonical co-integrating regression, " $\dagger$ " = statistically insignificant.

Table 2

Largest and Average Gaps of Impact Coefficients of G, I, and C, China 1980-2014

\begin{tabular}{|c|c|c|c|c|c|}
\hline & $\begin{array}{c}\text { 1980-1988 } \\
\triangle,_{1}\end{array}$ & $\begin{array}{c}\text { 1989-2007 } \\
\triangle_{{ }_{2}}\end{array}$ & $\begin{array}{c}\text { 2008-2014 } \\
\triangle_{{ }_{3}}\end{array}$ & $\begin{array}{c}\mathbf{1 9 8 0 - 1 9 8 8} \\
\succ_{, 1}\end{array}$ & $\begin{array}{c}1989-2014 \\
\diamond_{, 23}\end{array}$ \\
\hline Gap of $(G, I)$ Pair & 0.1108 & 0.308 & 0.0699 & 1.2703 & 0.0953 \\
\hline Gap of $(I, C)$ Pair & 0.4972 & 0.290 & 0.3666 & 0.4690 & 0.3968 \\
\hline Gap of $(\mathrm{C}, \mathrm{G})$ Pair & 0.608 & 0.598 & 0.2967 & 1.3573 & 0.4921 \\
\hline Average of All Gaps & 0.5711 & 0.399 & 0.2444 & 1.0322 & 0.3281 \\
\hline Largest Gap & 0.608 & 0.598 & 0.2967 & 1.2703 & 0.4921 \\
\hline
\end{tabular}

$\mathrm{G}=$ Government consumption, $\mathrm{I}=$ Private investment, $\mathrm{C}=$ Private consumption.

From Table 2 (constructed from Table 1), by the CCR measures (seeing $\triangle_{g_{1}} \rightarrow \triangle_{9_{2}}$ $\rightarrow \triangle,_{3}$ ), one observes that: (i) the largest gap of the pairs of the impact coefficients of $G$, I, and C has decreased over time $(0.608 \rightarrow 0.598 \rightarrow 0.2967)$; and (ii) the average gaps of $\mathrm{G}, \mathrm{I}$, and $\mathrm{C}$ have decreased over time as well $(0.5711 \rightarrow 0.399 \rightarrow 0.2444)$. As the results of employing JCM (seeing $\diamond_{, 1} \rightarrow \diamond_{, 23}$ ), it shows: (i) the largest gap of the pairs of the impact coefficients of $\mathrm{G}, \mathrm{I}$, and $\mathrm{C}$ has decreased over time $(1.2703 \rightarrow 0.4921)$; and (ii) the average gap of G, I, and C has decreased over time as well $(1.0322 \rightarrow 0.3281)$. Both of these results exhibit the unmistakable trend of decreasing from a higher level to a lower level of strategic discontinuity. And this is consistent with the downward trend in terms of the dynamics of strategic discontinuity predicted theoretical in Section 1 and actually detected in Section 3.

From the information of vectors provided in Table 2 comprising the impact coefficients on GDP of government expenditure, private investment, and private consumption: $\bigcirc, 1$ ' corresponding to $(0.1415,0.2523,0.7495)$ in $\bigcirc_{1}, \bigcirc_{, 2}$ ' corresponding to $(0.078$, $0.386,0.676)$ in $\bigcirc_{2}$, and $\bigcirc_{3}$ ' corresponding to $(0.2135,0.1436,0.5102)$ in $\bigcirc_{3}$, a threedimensional figure can be constructed as Figure 5.

In Figure 5, all the vectors of the impact coefficients of government consumption $(\mathrm{G})$, private investment (I), and private conception (C) on GDP in states of strategic discontinuity are plotted on the same graph. Then, these vectors are seen to converge over time

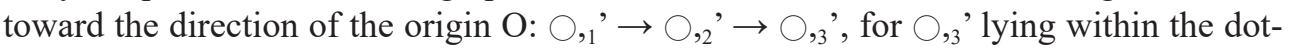
ted circle (which is intuitively drawn, and yet actually calculable) with these numerical labels, such as $\bigcirc_{11}, \bigcirc_{, 2}$, and $\bigcirc_{, 3}$, , been introduced in Table 1 .

Thus, one may conjecture as follows. (1) The "ultimate point of strategic discontinuity" with regard to G, I, and C of the Chinese economy may locate in the origin-centered circle with a small to moderate radius. (2) In the case of China, the realm of strategic discontinuity might converge toward (but would not reach) the origin $\mathrm{O}$ over time, with 
the radius of convergence having a natural lower bound. If so, this appears to imply the Chinese economy is becoming more stable and so far relatively more efficient, and the degree of strategic discontinuity of China has been diminishing over time associated with the diminishing momentum of China's economic growth.

Figure 5. Impact Coefficients on GDP and Converging Trajectory, China 1980-2014

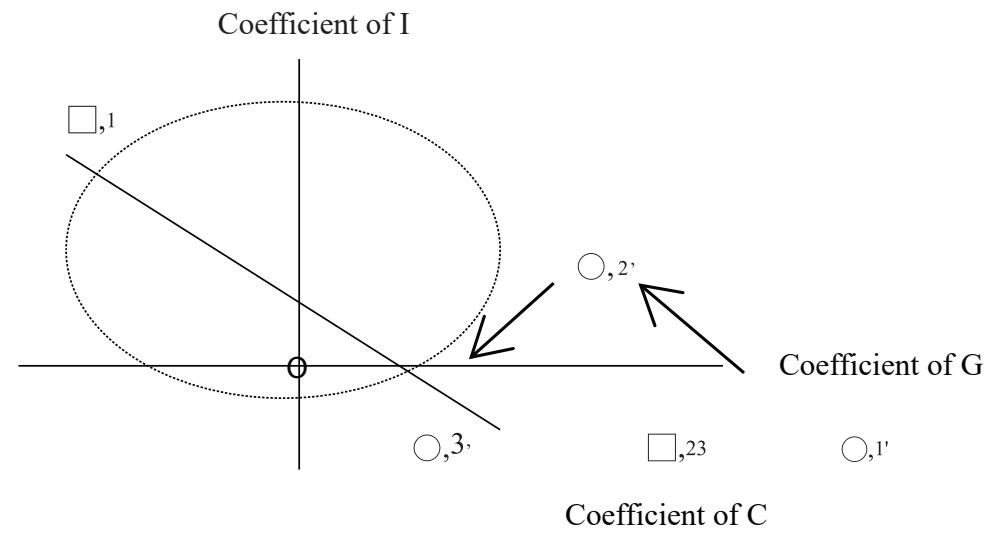

$\square{ }_{,_{1}}=\mathrm{JCM} 1980-1988, \square{ }_{2_{23}}=\mathrm{JCM} 1989-2014, \bigcirc_{,_{1}}=\mathrm{CCR} 1980-1988, \bigcirc_{,_{2}}=\mathrm{CCR} 1989-2007, \bigcirc_{,_{3}}=\mathrm{CCR}$ 2008-2014, $\bigcirc,{ }_{1}{ }^{\prime}=$ from $\bigcirc_{, 1}, \bigcirc_{, 2}{ }^{\prime}=$ from $\bigcirc_{, 2}, \bigcirc_{, 3}{ }^{\prime}=$ from $\bigcirc_{, 3}$.

Evidently, the message presented in Figure 5 is fundamentally consistent with the results of Section $2 .^{3}$

\section{Concluding Summary and Remarks}

The strategic initiatives of the Chinese economy in periods of 1980-1988, 19892007, and 2008-2014 are succinctly investigated, and our theory provides a rationale for the direction of weakening dynamics of strategic discontinuity over time for the Chinese economy.

To conduct an econometric study of the Chinese economy in these periods, the technique of Granger causality tests on dynamic VECM models is then employed. Subsequently our findings through the CCR method and JCM reveal that private consumption had the highest elastic impacts upon GDP with coefficients decreasing over time, exports and private investment had moderately elastic impacts with varying

${ }^{3}$ (Also see (6) Results of Appendix B). The empirical results differ somewhat from the evolutionary process of systemic structural changes due to several developments. The costs of the political turmoil of China in 1989 include for a while some degree of isolation of the Chinese economy from the economies of the West and Japan. Especially the government sector was then affected, and the marginal contribution of government consumption went down to deviate from the theoretical trajectory on which the marginal contributions of government consumption and private investment are expected to increase. 
values of coefficients, and government consumption had elastic impacts with coefficients changing from small positive (or negative) to moderately positive values over time. Finally, assessed from transforming vectors of the impact coefficients of government consumption, private investment, and private consumption, the trajectory of the Chinese economy traversing from higher level to lower level states of strategic discontinuity is clearly demonstrated. Therefore, the consistency between our theory of strategic discontinuity and the Chinese reality in this period of study is evidently confirmed.

Thus, following the world's second trend of convergence toward a mixed economy, we have provided a new useful framework to study the Chinese economy by the approach of searching for the strategic discontinuity among the forces of government consumption, private investment, and private consumption. ${ }^{4}$ This approach of ours is implicitly rooted in the framework of production and consumption. In contrast, the conventional macroeconomic approach (including that of stochastic dynamic general equilibrium) is based upon the foundation of aggregate demand and aggregate supply equilibrium.

Now a few remarks are warranted. First, our findings revealed the prominent impact coefficients of the private consumption on the real GDP and the moderate impact coefficients of exports and government consumption. Secondly, our finding of the significant impact coefficients of the private consumption on GDP confirms the general perception about the Chinese economy of the past as a production-oriented economy. Due to "under consumption," the "marginal contribution in percentage term" of private consumption was higher than those of all other variables according to the CCR method. Thirdly, the finding of the impact coefficient of government expenditure before 1989 (by Johansen cointegration model JCM) to be negative is somewhat surprising. Although it may point to the direction of government failure, there may also exist some hidden causes such as the necessity of an early stage of national building to justify its role at the time. Last but not least, in this period, the converging trajectory of strategic discontinuity of China is inferred as the trend of moving partially and limitedly toward the equalization of sectoral contributions to the economy. This appears to be a welcoming trend, and it confirms well the consistency between our theory of strategic discontinuity and the Chinese reality in this period of study.

\section{Appendix A Table of Model Selection}

Seeing Tables A.1 and A.2, there are 4 to 5 sets of co-integration relation verified by judging from the trace of maximum eigenvalues of co-integration relations. It follows that, by the criterion of SC selection, we identify the second model, or the one with longterm intercept but without any trend term.

${ }^{4}$ With regard to Appendix B, this new framework seeks to explore the strategic discontinuity or cross-sectional systemic imbalance among the forces of centrality, mutuality, and competition, applicable both to the production/aggregate supply and consumption/aggregate demand sides of the modern economy. 
Date: $12 / 16 / 14$ Time: $17: 31$

Sample: 1102

Included observations: 96

Series: LNC LNEX LNFDI LNG LNGDP LNI LNIMPORTS

Lags interval: 1 to 5

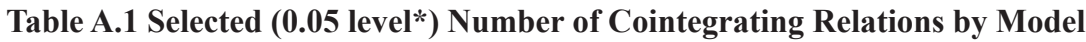

\begin{tabular}{|c|c|c|c|c|c||}
\hline \hline Data Trend: & None & None & Linear & Linear & Quadratic \\
\hline Test Type & No Intercept & Intercept & Intercept & Intercept & Intercept \\
\hline & No Trend & No Trend & No Trend & Trend & Trend \\
\hline Trace & 4 & 5 & 4 & 5 & 4 \\
\hline Max-Eig & 2 & 3 & 2 & 4 & 4 \\
\hline
\end{tabular}

* Critical values based on MacKinnon-Haug-Michelis (1999).

Table A.2 Information Criteria by Rank and Model

\begin{tabular}{|c|c|c|c|c|c||}
\hline \hline Data Trend: & None & None & Linear & Linear & Quadratic \\
\hline Rank or & No Intercept & Intercept & Intercept & Intercept & Intercept \\
\hline No. of CEs & No Trend & No Trend & No Trend & Trend & Trend \\
\hline \multicolumn{7}{|c|}{ Log Likelihood by Rank (rows) and Model (columns) } \\
\hline 0 & 1625.331 & 1625.331 & 1637.250 & 1637.250 & 1644.796 \\
\hline 1 & 1655.505 & 1657.946 & 1669.861 & 1670.515 & 1677.237 \\
\hline 2 & 1674.742 & 1683.458 & 1695.230 & 1696.476 & 1702.632 \\
\hline 3 & 1687.740 & 1702.388 & 1711.900 & 1720.077 & 1726.178 \\
\hline 4 & 1700.403 & 1715.328 & 1724.792 & 1736.746 & 1742.729 \\
\hline 5 & 1707.487 & 1727.047 & 1731.810 & 1747.783 & 1752.141 \\
\hline 6 & 1711.089 & 1733.703 & 1736.650 & 1754.797 & 1758.762 \\
\hline 7 & 1711.213 & 1737.121 & 1737.121 & 1758.799 & 1758.799 \\
\hline \multicolumn{7}{|c|}{ Schwarz Criteria by Rank (rows) and Model (columns) } \\
\hline 0 & $-22.21247 *$ & $-22.21247 *$ & -22.12797 & -22.12797 & -21.95236 \\
\hline 1 & -22.17546 & -22.17876 & -22.14172 & -22.10780 & -21.96257 \\
\hline 2 & -21.91060 & -21.99708 & -22.00461 & -21.93549 & -21.82601 \\
\hline 3 & -21.51574 & -21.67828 & -21.68626 & -21.71399 & -21.65090 \\
\hline 4 & -21.11392 & -21.23469 & -21.28922 & -21.34808 & -21.33009 \\
\hline 5 & -20.59588 & -20.76566 & -20.76980 & -20.86483 & -20.86053 \\
\hline 6 & -20.00528 & -20.19114 & -20.20500 & -20.29778 & -20.33284 \\
\hline 7 & -19.34224 & -19.54917 & -19.54917 & -19.66797 & -19.66797 \\
\hline
\end{tabular}

\section{Appendix B Systemic Changes of Human Activism in States of Strategic Discontinuity}

(1) ADV 1. This is the period in which the cultural backgrounds of the economy are starting to transform from $\mathrm{Cul} \mathrm{I}$ to a mix of $\mathrm{Cul} \mathrm{I}$ and $\mathrm{Cul} \mathrm{II.} \mathrm{Here,} \mathrm{Cul} \mathrm{I} \mathrm{is} \mathrm{the} \mathrm{cultural}$ system of groupism with wealth accumulation at the household level (i.e., the household's objective being the maximization of wealth accumulation) under the institution of group-oriented family (for passing wealth to the offspring) and with national surplus maximization (or practically maintaining high-level GDP growth rates) at the national 
level under the institution of HA I (human activism I, i.e., the structures of Confucian guanxi-network at the social level and central planning and SOEs at the national level). In contrast, $\mathrm{Cul} \mathrm{II} \mathrm{is} \mathrm{the} \mathrm{cultural} \mathrm{system} \mathrm{of} \mathrm{(capitalistic)} \mathrm{individualism} \mathrm{oriented} \mathrm{toward}$ consumption (i.e., striving for maximizing the value of consumption and service goods measured in subjective prices) and technological creation at the household level under the institution of individualistic family (competitive or even imperfect market being the background) and with consumption maximization (or practically the goal of full employment) at the national level under the institution of HA II (human activism II, i.e., structures of government interventions conducive to fiscal, monetary, and other government policies and regulatory measures).

(2) ADV 2. This is a process of transforming a closed economy into an open economy by internalizing foreign commercial forces and advanced technologies. Naturally, the background is the development of the domestic economy.

(3) ADV 3. With the notations of "H+" depicting the idea of "extremely high level," "H" the idea of "high level," "M" the idea of "medium level," "L" the idea of "low level," and "L-" the idea of "extremely low level," now we have $\left(\mathrm{Z}^{\mathrm{H}+}, \mathrm{M}^{\mathrm{L}}, \mathrm{K}^{\mathrm{L}-}\right)$ denoting the HA Hybrid, with "H+" force of centrality $\mathrm{H}$, "L" force of mutuality M," and "L-" force of market competition $\mathrm{K}$.

(4) ADV4. With the notations of "H+" depicting the idea of "extremely high level," "H" the idea of "high level," "M" the idea of "medium level," "L" the idea of "low level," and "L-" the idea of "extremely low level," it is assumed to have a long-term trend of continual decline in the degree of strategic discontinuity for the first three stages as follows: " $\left(\mathrm{Z}^{\mathrm{H}+}, \mathrm{M}^{\mathrm{L}}, \mathrm{K}^{\mathrm{L}-}\right) \leftrightarrow$ developing defense industry, agriculture, and light industries" $\rightarrow$ " $\left(Z^{\mathrm{H}}, \mathrm{M}^{\mathrm{M}}, \mathrm{K}^{\mathrm{L}}\right) \leftrightarrow$ developing defense industry, agriculture, light industries, and heavy-chemical industries" $\rightarrow$ " $\left(\mathrm{Z}^{\mathrm{M}}, \mathrm{M}^{\mathrm{H}}, \mathrm{K}^{\mathrm{M}}\right) \leftrightarrow$ developing defense industry, high-tech industries, finance, and international trade" $\Rightarrow$ "Slow growth path $\rightarrow$ rapid growth path $\rightarrow$ approach/moderate growth path." Here $\left(\mathrm{Z}^{\mathrm{H}}, \mathrm{M}^{\mathrm{M}}, \mathrm{K}^{\mathrm{L}}\right)$ denotes HA Hybrid of stage 2, and $\left(\mathrm{Z}^{\mathrm{M}}, \mathrm{M}^{\mathrm{H}}, \mathrm{K}^{\mathrm{M}}\right)$ denotes HA Hybrid of stage 3 .

(5) Results. Three results are implied by ADV1-AD4. (1) The force of strategic discontinuity of a system would not cease if the strategic objectives of the system are not achieved and if there exist potentials of systemic and strategic changes. (2) The force of strategic discontinuity of a system would not cease if the state of the system is not satisfactory to the planner and if there exist potentials of systemic and strategic changes. (3) In the process of decreasing the degree of strategic discontinuity, the difference among the forces of centrality, mutuality, and competition shall shrink; as such, the differential marginal contributions of the forces of centrality, mutuality, and competition would shrink over time accordingly.

To be connected to the econometric study of China presented in this paper, the important consequence for the formulation of the evolutionary process of an advancing economy is the shrinking state of strategic discontinuity. That is to say, in terms of the concepts of centrality, mutuality, and competition, as the economy advances over time, the divergent forces of centrality, mutuality, and competition shall reduce their respective momentum, and thus the degree of strategic discontinuity among them shall be reduced over time (also see Section 3 of this paper). That is, for an advancing economy, with the forces of centrality $(Z)$, mutuality $(M)$, and competition $(K)$ embedded in Hybrid HA, 
let $\mathrm{Y}$ be the real output, and $\mathrm{Z}, \mathrm{M}$, and $\mathrm{K}$ be the real outputs of the sectors of centrality, mutuality, and competition of the domestic economy, respectively. Then we have:

$$
Y=Z+M+K+F
$$

with F referring to the real output of the foreign sector. Moreover we have:

$$
\frac{\partial \ln Q}{\partial \ln Z}=a \frac{\partial \ln Q}{\partial \ln M}+b=c \frac{\partial \ln Q}{\partial \ln K}+d
$$

as a necessary condition of strategic discontinuity (for more details, also see Formula (1)).

Note that, for this $Z$ in Formula (15), one may assume $\Delta Y^{Z}=\tau_{z} \cdot \Delta \mathrm{Z}$, for $\tau_{z}$ being transformational operator of production out of the sector of centrality, $\Delta Y^{z}$ being the change in the real output of the economy out of centrality. Furthermore, one could have: $\tau_{z}=\alpha^{\prime \prime} \times \beta^{\prime \prime} \times \gamma^{\prime \prime}, \alpha^{\prime \prime}>\beta^{\prime \prime} \geq 1>\gamma^{\prime \prime}>0$, with $\gamma^{\prime \prime}=\frac{1}{1+\beta^{\prime \prime}}$ and $\alpha^{\prime \prime}=\frac{1}{1-F T L}$; for $\alpha^{\prime \prime}$ being the value associated with of the force of centrality, with $0 \leq$ FTL $<1$, FTL being the fraction of total investment devoted to the sector/operations of centrality, $\beta$ " being the value associated with the sector/operations of competition and $\gamma^{\prime \prime}$ being the value associated with mutuality. For example, $\tau_{z}=\alpha^{\prime \prime} \times \beta^{\prime \prime} \times \gamma^{\prime \prime}=10 \times 2 \times \frac{1}{3}=\frac{20}{3}$ by assuming FTL $=$ $0.9, \beta "=2$. Similarly, one could have analogous formulae for the variables M and K.

The cultural system of Confucianized Legalism (內法外儒 nefa wairu, Confucianism outside with Legalism inside) with institutions of central planning mechanism and the Chinese Communist Party is necessary for the force of centrality the way it practiced so far in China, and the cultural system of Confucianism is necessary for the force of mutuality the way it practiced in China to this date. What is special about the Chinese cultures is that both of these Legalism and Confucianism share the same root with Taoism, and therefore the Chinese "relative centrality" and "relative inward-looking mutuality" (i.e., not to be excessive reciprocal as to avoid coercion and corruption) have great potentialities to evolve into a form of modernization. Over time, in essence, these traditional cultural foundations would be in conflict with the transplanted cultures of Marxism-Leninism and capitalism.

It is insightful to compare with the experience of the former Soviet Union in which the integration of the forces of market with central planning failed miserably. The success story of China so far has essentially been about the contributions of the role of mutuality playing in a strong form HA. Through the intermediary function of guanxi network (force of mutuality, for examples, the guanxi network supporting the establishment of shadow banking system on one side and the CCP operations on the other side) to bridge the gap between central planning system and capitalist market system, the Chinese economy has achieved reasonably (or a somewhat acceptable degree of) smooth operations of both SOEs and private business sector. In terms of economic institution, it is this guanxi network based on Confucian ethics that enables China to engage successfully in a continual series of economic reforms, and in terms of economic structure, it is the lack of this type of the mechanism of mutuality that the former Soviet Union failed. In this case of China, underlying the forces of centrality, mutuality, and competition, the cultural basis of Tao- 
ist activism (i.e., active but not passive Taoism) is indispensable. That is, without this active (and somewhat inward-looking) ethics and (systemic/holistic) rationality of Taoism, the Chinese system of human activism would not operate effectively and smoothly. Evidently, different cultural forces have contributed to the different experiences of China and the former Soviet Union in terms of economic reforms. ${ }^{5}$

The new ideas presented in this paper are included in order to fit for the study of an advancing economy of nations (for instance, China, and similarly for Japan, India, and some Islamic countries, etc.), with the necessary bases of cultures and institutions to be internalized.

The trajectory for the future (or stage 4 dynamics) of China may also lie fundamentally in, while keeping the efficiency of centrality and mutuality intact, internalize the culture of the West in individual spontaneity and scientific creativity through a process of creating new culture from the bases of Hybrid Cul and Hybrid HA. In general, it is hard to successfully learn from the West, and it is extremely difficult to create a new culture.

\section{Bibliography}

Blanchard O. J., Quah D. (1989), The Dynamic Effect of Aggregate Demand and Supply Disturbances, "The American Economic Review," 79 (4), September, pp. 655-673.

Cao J., Ho M. S., Jorgenson D. W., Ren R., Sun L., Yue X. (2009), Industrial and Aggregate Measures of Productivity Growth in China, 1982-2000, "The Review of Income and Wealth," Series 55, Special Issue 1, July, pp. 485-513.

Chang S. (2012), Socialist Market Economy Does Not Operate According to Keynesianism, "Zhongguo Qingnian Bao,” http://views.ce.cn/view/ent/2012/08/13/201208/13/t20120813_23577639. shtml, 8.13.2012.

Cheng K. T. (2007), State-owned Enterprise Reform in People's Republic of China, "Journal of Pingtung Education University-Humanities and Social Sciences,” 27, June, pp. 1-38.

Chris C. (2014), China May Become the Largest Economy of the World, "Financial Times," http://big5. ftchinese.com/story/001056024, 20.04.2014.

Coase R., Wang N. (2012), How China Became Capitalist?, Palgrave Macmillan, New York.

Davison P. (2007), John Maynard Keynes, Palgrave Macmillan, New York.

Dees S. (1998), Foreign Direct Investment in China: Determinants and Effects, "Economics of Planning," 31, pp. 175-194.

Démurger S. (2001), Infrastructure Development and Economic Growth: An Explanation for Regional Disparities in China?, "Journal of Comparative Economics," 29, pp. 595-117.

Engle R. F., Granger C. W. J. (1987), Co-integration and Error Correction: Representation, Estimation and Testing, "Econometrica," 55, pp. 251-276.

Fukuyama F. (2015), Special Interview with Fukuyama: What is Chinese Model, Nikkei Chinese, http:// zh.cn.nikkei.com/columnviewpoint/1258020150115.

html?start=1, 15.01.2015.

${ }^{5}$ In the near future, in general, it is pointed out that this advancing economy may be stagnating (in stage 4), and an apparent direction to rejuvenate this system is to move onto the trajectory of a matured economy of the West. By the words of Fukutama (2015), a fundamental problem for the existing "Chinese model" is that it is composed the philosophy of "Marxism-Leninism and Confucianism" and "both are not compatible," and further incorporate the spirit of "selfishness." This is a system "without consistent philosophy." 
Galí J (2008), Monetary Policy, Inflation, and the Business Cycle: An Introduction to the New Keynesian Framework, Princeton University Press, Princeton, N.J.

Graham E. M., Wada E. (2001), Foreign Direct Investment in China, in: Achieving High Growth: Experience of Transitional Economies in East Asia, ed. P. Drysdale, Oxford University Press, Oxford.

Hu A. (2010), Falsification of the Public Forward and Private Backward, http://aisixiang.com/ data/51767-2.html, 31.03.2010.

Hu Z., Khanp M. S. (1997), Why Is China Growing So Fast?, "IMF, Economic Issues," 8, Washington D.C.

Kaldor N. (1980), Monetarism and UK economic policy, "Cambridge Journal of Economics," 4, pp. 271-218.

Kwan A. C., Wu Y., Zhang J. (1999), Fixed Investment and Economic Growth in China, "Economics of Planning," 32, pp. 67-79.

Lin S. (1999), Export Expansion and Economic Growth: Evidence from Chinese Provinces, "Pacific Economic Review," 4:1, pp. 65-77.

Lin J., Cai F., Li Z. (1997), Reforms and Development of the Chinese Economy, Lieng Ching, Taipei.

Lin J. (2012), Demystifying the Chinese Economy, Beijing Daxue, Beijing.

Liu X., Burridge P., Sinclair P. J. N. (2002), Relationships between economic growth, foreign direct investment and trade: evidence from China, "Applied Economics," 34, pp. 1433-1440.

Lum T., Nanto D. K. (2002), China's Trade with the United States and the World, "Congressional Research Service," Order Code RL31403, The Library of Congress.

Mankiw N. G., Romer D. (eds.) (1991), New Keynesian Economics, vol. 1: Imperfect competition and sticky prices, MIT Press, vol. 2: Coordination Failures and Real Rigidities, MIT Press.

Minsky P. H. (1957), Central Banking and Money Market changes, "The Quarterly Journal of Economics," vol. LXXI, no. 2 (May), pp. 171-187.

Minsky H. P. (1992), The Financial Instability Hypothesis, "The Jerome Levy Economics Institute of Bard College," Working Paper no. 74, May 1992.

Ning L. (2009), China's Rise in the World ICT Industry: Industrial Strategies and the Catch-Up Development Model, Routledge, New York.

Qiao Y (1998), Capital Investment, International Trade and Economic Growth in China: Evidence in the 1980-90s, "China Economic Review" (1043951X), Spring, 9(1), p. 73.

Robinson J., Eatwell J. (1974), An Introduction to Modern Economics, McGraw-Hill Inc., US.

Romer D. (2012), Advanced Macroeconomics, $4^{\text {th }}$ ed., McGraw-Hill, New York.

Sahoo P., Dash R. K., Nataraj G. (2012), China's Growth Story: The Role of Physical and Infrastructure, "Journal of Economic Development," 37, 1, March, pp. 53-75.

Serger S. S. (2009), Foreign Corporate R \& D in China: Trend and Policy Issues, in: The New Asia InnovationDynamics: China and India in Perspectives, eds. P. Govindan, A. P. D'Costa, Palgrave Macmillan, New York.

Shi Z. (2010), The Making of the Chinese economic Miracle?, "Financial Times," http://big5.ftchinese. com/story/001054336?full=y, 14.01.2014.

Sraffa P. (1960), Production of Commodities by Means of Commodities: Prelude to a Critique of Economic Theory, Cambridge University Press, Cambridge-New York.

Tonn V. L. (2009), Systematics and The Economics of Culture, Peter Lang GmbH, Frankfurt am Main.

Tonn V. L. (2014), Cultures and Sino-American Catching-up Advancement: Ecultrnomics as an Approach of Xystematics, in: Chinese culture in a crosscultural comparison, ed. M. B. Hinner, Peter Lang, New York, pp. 529-567.

Tonn V. L. (2016), Democratic Confucianism and Human Activism of Centrality, Mutuality/Cocreativity, and Competition in Transformational Holistics, "China Media Research," 12(4), pp. 18-36. 
Tonn V. L. (2018), Yin Yang Framework of Strategic Discontinuity, Doctrine of Renyi/Contingency of Transformational Holistics, and Capitalist Confucianism. Delivered at the $24^{\text {th }}$ International Conference of International Association of the Intercultural Communication Studies (IAICS), DePaul University, Chicago, July 5-8, 2018.

Turpin T., Liu X. (2000), Balanced Development: The Challenge for Science, Technology, and Innovation Policy, in: Contemporary Developments and Issues in China's Economic Transition, ed. C. Harvie, St. Martin's Press, New York.

Wei Y., Liu X., Song H., Romilly P. (2001), Endogenous Innovation Growth Theory and Regional Income Convergence in China", "Journal of International Development," 13, pp. 153-168.

Wikipedia (2015), Post-Keynesian Economics, http://en.wikipwdia.org/wiki/Post-Keynesian_economics, January 10, 2015.

Williamson J. (2012), Is the "Beijing Consensus" Now Dominant?, “Asia Policy," 13 (January).

Woodford M. (2003), Interest and Prices: Foundations of a Theory of Monetary Policy, Princeton University Press, Princeton, N.J.

Wu J. (2013), The Choice of China's Growth Model, Shanghai Yuan Dong, Shanghai.

Yueh L. (2013), China's Growth: The Making of an Economic Superpower, Oxford University Press, Oxford.

Zhang W. (2012), “What changes China?,” Zhongguo Jingji Wang, http://book.ce.cn/read/economy/ smgbzg/201207/09/t20120709 23473397 31.shtml, 9.07.2012.

Zhang J. (2013), The Chinese Economy Misunderstood, Dongfang Chubanshe, Beijing.

\section{Dochód narodowy, strategiczna nieciągłość i zbieżne trajektorie inicjatyw polityki makroekonomicznej: empiryczne badania dotyczące Chin}

\section{Summary}

Ramy zbieżnych trajektorii inicjatyw polityki makroekonomicznej są stosowane w kontekście strategicznej nieciągłości w badaniu dochodu narodowego rozwijającej się gospodarki. Przedstawiono model zmian systemowych opartych na równaniu produkcji i konsumpcji. W analizie chińskiej gospodarki z lat 1980-2014 z biegiem czasu zauważalna jest znaczna redukcja dynamiki nierównowagi politycznej, co jest zgodne ze spadkową tendencją zmniejszania się różnic pomiędzy współczynnikami wpływu konsumpcji publicznej, inwestycji prywatnych i konsumpcji prywatnej.

Słowa kluczowe: nieciągłość strategiczna, zmiany systemowe, testy ekonometryczne, postęp ekonomiczny, Chiny 